\title{
NONRSSING PRACTICES
}

\section{Wiwiek Retti Andriani' ${ }^{1}$ Elsye Peningkatan Capaian Kompetensi Kognitif Maria Rosa ${ }^{2}$, Moh. Afandi ${ }^{2}$ \\ ${ }^{1}$ Akper Ponorogo \\ ${ }^{2}$ Universitas Muhammadiyah Yogyakarta Email: reregoe@gmail.com \\ Mahasiswa Akper Pemkab Ponorogo dengan Penerapan Peer-Assisted (PAL)}

\begin{tabular}{ll}
\hline Info Artikel & $:$ \\
Masuk & $: 25$ Juli 2017 \\
Revisi & $: 10$ November 2017 \\
Diterima & $: 30$ Novermber 2017 \\
DOI Number & $: 10.18196 /$ ijnp.1368
\end{tabular}

Proses pembelajaran yang ditekankan saat ini adalah student centered learning yang memberikan kesempatan mahasiswa untuk membangun sendiri pengetahuannya sehingga akan memperoleh pemahaman mendalam. Salah satu pembelajaran inovatif dengan strategi student centered learning yaitu Peer-Assisted Learning (tutor sebaya). Metode PAL mampu meningkatkan pemahaman (secara kognitif) pada tutor dan tutees, dikarenakan konsep-konsep dapat dijelaskan secara sederhana dengan menggunakan bahasa yang paling mudah difahami dan sesuai dengan level mahasiswa. Konsep ini dikenal sebagai konsep keselarasan kognitif(cognitive congruence). Tujuan penelitian ini adalah menganalisis penerapan metode peer-assisted learning (PAL) dalam meningkatkan pencapaian kompetensi kognitif mahasiswa.

Penelitian ini menggunakan desain quasy experiment dengan rancangan pre and post-test with control group design. Tehnik sampling menggunakan simple random sampling, dengan sampel sejumlah 60 mahasiswa semester empat yang terbagi menjadi dua kelompok perlakuan dan kontrol. Instrumen penelitian menggunakan multiple choice question. Data dianalisis menggunakan t-test, dengan $\alpha=0.05$.

Hasil uji statistik menunjukkan bahwa rata-rata nilai pre-test dan post-tes $t$ mengalami perubahan signifikan ( $p$ value 0.000 ). Nilai rata-rata pre-test $(42,40)$ termasuk dalam kategori tidak kompeten sedangkan nilai rata -rata post-test $(84,27)$ sehingga termasuk dalam kategori kompeten. Sedangkan pada kelompok kontrol sebelum perlakuan nilai mean $(40,67)$ termasuk dalam kategori tidak kompeten. Setelah mendapatkan intervensi non-PAL, nilai mean meningkat menjadi $(69,60)$ termasuk kategori tidak kompeten. Penerapan peer-assisted learning berpengaruh signifikan untuk meningkatkan kompetensi kognitif mahasiswa.

Kata kunci: Aplikasi, Peer-assisted Learning (PAL), kompetensi kognitif.

\section{Abstract}

The learning process that is emphasized today is student centered learning, this learning provides an opportunity student to build their own knowledge so that gain a deep understanding. One of innovative learning with student centered learning strategy is Peer-Assisted Learning (peer tutor). The PAL method is able to improve understanding (cognitively) on tutor and tutees, as concepts can be explained simply by using the easiest language to understand and match the student level. This concepts is know as the concept of cognitive alignment (cognitive congruence). The aim of the research is to analyze the application of PAL method to increase the achievement of students' competency.

The research used quasi-experimental design, pre and post-test plan with 


\section{NURONSIAN DOUNANG \\ PRACTICES}

control group design. The sampling technique was simple random sampling. The samples were currently fourth semester students, 60 students were divided in 2 groups, treatment group and control group. The instrument was multiple choice questions for cognitive competency evaluation and checklist for psychomotor competency and affective evaluation. Data were analyzed by using T-test, with 0.05 degree of significance.

The result showed that the average value of pre-test and post-test examination experiencing significant changes $(p=0.000)$. The average value of pre-test (42.40) was categorized incompetence, while the average value of post-test (84.27) was classified as competence. Whereas in control group before implementation of PAL the mean value was 40.67. It was classified as incompetence. After PAL intervention it increased into 69.60 or categorized as competence. It was concluded that there was significant influence of PAL application to improve students' cognitive competence.

Keywords: applications, Peer-assisted Learning (PAL), cognitive competence

\section{Pendahuluan}

Kurikulum pendidikan saat ini mengarah pada pendekatan kompetensi. Mahasiswa dituntut untuk menguasai ilmu pengetahuan, attitude, juga keterampilan klinik (Mulder, 2006). Kurikulum pendidikan saat ini mengamanahkan perubahan pendekatan pembelajaran teacher centered learning ke metode student centered learning. Metode belajaryang lebih menekankan pada keaktifan mahasiswa, saat ini mulai banyak digunakan untuk lebih mendorong partisipasi aktif dan berpikir kreatif.

Metode pembelajaran yang diterapkan di lingkungan Akper Pemkab Ponorogo sebagian besar cenderung pada pembelajaran yang bersifat konvensional (teachercentered learning). Hal ini menjadikan mahasiswa pasif, cenderung hanya mendengar, komunikasi satu arah, tidak ada diskusi dengan teman terkait materi yang harus dikuasai.

Diperlukan adanya metode pembelajaran yang membuat mahasiswa berinteraksi dengan teman dan aktif diskusi untuk mengasah kemampuan berfikir kritis. Ladyshewsky (2000, dalam Tice, 2014) menyatakan bahwa pembelajaran kooperatif merupakan strategi yang baik untuk meningkatkan hasil pendidikan dan sangat berguna untuk mengembangkan kompetensi siswa. Salah satu metode yang di tawarkan adalah Peer-Assisted Learning (PAL) (Stone,
Cooper, \& Cant, 2013). Peer-Assisted Learning (PAL) merupakan salah satu metode atau strategi pembelajaran yang bersifat student center learning karena dianggap sebagai suatu metode pembelajaran kolaboratif, kooperatif dan memberikan manfaat secara akademik bagi mahasiswa (Santee \& Garavalia, 2006; Secomb J, 2008; Yu et al., 2011). Menurut Tice (2014) salah satu dasar teoritis untuk semua jenis peer teaching dan learning adalah cooperative learning. Perspektifyang mengarahkan penelitian dan pengembangan cooperative learning adalah interaksi sosial, perkembangan kognitif dan teoriteori perilaku belajar.

Penggunaan PAL dalam program pendidikan kesehatan medis, keperawatan, terapi fisik, terapi okupasi, obat-obatan, pelatihan atletik, dan pendidikan tinggi, merupakan strategi pendidikan yang tepat digunakan karena menawarkan agar siswa aktif berpartisipasi (Henning, Weidner, \& Mellisa, 2008). Asistensi atau yang disebut juga Peer Assisted Learning (PAL) adalah suatu kegiatan pembelajaran dimana perolehan ilmu berasal dari rekan yang derajatnya sama dengan peserta yang menerima ilmu (Topping, 1996). Metode PAL ini dapat menggunakan mahasiswa sebaya pada satu tahun angkatan yang sama (peer-) maupun pada tahun angkatan yang berbeda namun tidak berjauhan (near-peer), dalam satu jenjang pendidikan yang setara (misalnya Diploma), maupun lintas jenjang, dalam 
satu institusi pendidikan maupun lintas institusi (Topping, 1996). Peer-Assisted learning merupakan salah satu implementasi pembelajaran dalam kelompok kecil yang bermanfaat untuk mengembangkan keterampilan berkomunikasi, pengembangan kompetensi intelektual dan professional, dan pengembangan kepribadian mahasiswa (Brown \& Atkins, 2002).

Metode Peer-Assisted Learning (PAL) terbukti memberikan manfaat secara akademik bagi mahasiswa pengajar (tutor) maupun peserta (tutees) (Yu, et al., 2011). Manfaat bagi mahasiswa (tutees), akan lebih akrab dengan tutor dibandingkan dengan fasilitator dosen, sehingga lebih mudah dalam proses pembelajaran (Sheldon; 1973 cit. Burke et al., 2007). Interaksi dengan rekan sebaya juga diketahui dapat meningkatkan rasa percaya diri dan komitmen untuk belajar, meningkatkan perhatian bersama antara peserta dan bermanfaat untuk peningkatan keterampilan (Topping \& Ehly, 1998; Buckley \& Zamora, 2007). Secara teori, hal yang diyakini mendukung keberhasilan PAL terletak pada adanya fakta bahwa tutor dan mahasiswa peserta (tutees) mempunyai pengetahuan dasar dan pengalaman yang sama, yang dikenal sebagai keselarasan kognitif (cognitive congruence). Adanya kesesuaian kognitif ini memungkinkan asisten mahasiswa memahami secara lebih mendalam tingkat pengetahuan, kebutuhan belajar, masalah kognitif yang dihadapi serta capaian yang diharapkan terhadap mahasiswa pesertanya sehingga asisten mahasiswa ini mampu menjelaskan konsep-konsep secara sederhana dengan menggunakan bahasa yang paling mudah difahami sesuai dengan level mahasiswa pesertanya (Ten Cate \& Durning, 2007a).

Keterampilan komunikasi bisa dilatih melalui metode Peer-assisted learning karena memberikan kesempatan kepada seluruh mahasiswa, baik tutor maupun tutee untuk mengemukakan ide, pendapat, pertanyaan, maupun jawaban dalam diskusi kelompok kecil. Pada saat yang sama, metode PAL juga bisa digunakan untuk melatih keterampilan berfikir. Tutor menyampaikan informasi yang berkaitan dengan materi secara terstruktur dan mudah dipahami oleh temannya. Tutee juga dituntut untuk mencerna, mengkritisi, dan bahkan menawarkan informasi baru yang berkaitan dengan materi yang disampaiakan oleh tutor. Dalam metode PAL, terdapat 4 prinsip yang saling berkaitan secara sistemik, yaitu respon aktif siswa, kesempatan bagi siswa untuk memberikan respon, umpan balik, serta penguatan (Heron, Villareal, \& Yao, 2006).

Model pembelajaran dengan PAL ini mampu menutup kesenjangan nilai antar mahasiswa, meningkatkan suasana akademik yang kondusif, budaya kolaborasi daripada kompetisi, situasi yang mendukung proses pembelajaran serta alternatif inovasi bagi institusi dengan keterbatasan sumber daya manusianya (Ross \& Cummings, 2009).

Teori dasar pengembangan model pembelajaran peer-assisted learning (PAL) adalah teori constructivism dari Jean Piaget, yang menyatakan bahwa tahap perkembangan kognitif melibatkan berbagai macam faktor, seperti: kematangan, pengalaman, dan faktor lingkungan sosial. Piaget berpendapat bahwa ketika orang menghadapi informasi baru yang tidak sesuai dengan pengaturan pengetahuan dan pemikiran mental mereka saat ini, sebuah kontradiksi yang menyebabkan ketidak seimbangan. Hal ini menyebabkan pelajar mengakomodasi informasi baru dan mengubah pemahaman sehingga mencapai keseimbangan. Dengan cara ini, pelajar membangun pengetahuan mereka sendiri. (Falchikov, 2001).

Sejalan dengan Piaget, teori zone of proximal development oleh Vygotsky (1978), menyatakan bahwa perkembangan kognitif membutuhkan interaksi sosial. Vygotsky menetapkan bahwa interaksi sosial memainkan peran penting dalam pengembangan kognisi (Vygotsky, 1986). Dukungan belajar dari rekan-rekan di "komunitas praktek", sebagai akibatnya, memberikan kesempatan bagi praktisi pemula untuk merenungkan proposisi pengetahuan (fakta dan konsep), pengetahuan kerajinan profesional (belajar dari pengalaman, keterampilan), dan pengetahuan pribadi (Donaghy, Carey \& Beeman, 1998 dalam Ibrahim, 2011). Vygotsky berpendapat bahwa berbagai keterampilan dapat dikembangkan dengan bimbingan orang dewasa atau kolaborasi dengan teman melebihi yang dapat dicapai sendiri. Pusat untuk teorinya 


\section{NURONSINAN DOUNA \\ PRACTICES}

adalah ide dari zone of proximal development (ZPD) yang berarti suatu zona perkembangan ketika anak tidak mampu melakukan suatu kegiatan belajar tanpa bantuan, namun dapat melakukannya secara baik dibawah bimbingan orang dewasa. Tingkat perkembangan ditentukan melalui pemecahan masalah di bawah bimbingan orang dewasa atau kolaborasi dengan rekanrekan yang lebih mampu (Toping, 1996; Falchikov, 2001; Ten Cate \& Durning, 2007).

Berdasarkan uraian di atas, maka didapatkan rumusan permasalahan: apakah penerapan model pembelajaran peer-assisted learning (PAL) mampu meningkatkan capaian kompetensi kognitif mahasiswa.

Penelitian ini diharapkan memperkaya konsep atau teori yang mendukung perkembangan ilmu keperawatan tentang model pembelajaran dengan pendekatan student centered learning $(\mathrm{SCL})$ dan dapat menjadi evaluasi dan masukan bagi pengeelola pendidikan (bagian akademik) Akper Pemkab Ponorogo dalam mengambil kebijakan untuk perbaikan program pembelajaran.

\section{Metode}

Populasi dalam penelitian ini adalah mahasiswa semester IV Akper Pemkab Ponorogo sejumlah 124 orang. Tehnik sampling yang digunakan adalah simple random sampling. Jumlah sampel dalam penelitian adalah 60 orang yang terbagi menjadi 2 kelompok, yaitu kelompok perlakuan $(n=30)$ dan kelompok kontrol $(n=30)$. Penelitian ini menggunakan pendekatan penelitian quasy experiment dengan desain pre-test and post-test with controlgroup design. Kelompok eskperime n dalam penelitian ini diberikan perlakuan penerapan model pembelajaran peer-assisted learning (PAL), sedangkan kelompok kontrol diberikan dengan metode pembelajaran konvensional ceramah dari dosen. Variabel bebas dalam penelitian ini adalah metode pembelajaran kooperatif peer-assisted learning (PAL), sedangkan variabel terikatnya adalah kompetensi kognitif.

Penelitian dilakukan dari bulan Oktober 2016 sampai bulan Februari 2017 di Akper Pemkab
Ponorogo melalui rangkaian prosedur, meliputi: 1) Tahap pemilihan tutor dilakukan oleh tim pengajar dan bekerjasama dengan kemahasiswaan untuk seleksi tutor, 2) Tahap briefing tutor yang dilakukan oleh koordinator mata kuliah dan tim pengajar. Briefing tutor dilakukan sebanyak 4 kali tatap muka/session. 3) Evaluasi kesiapan dan pemahaman tutor tentang materi yang telah diberikan saat briefing, 4) Tahap pre-test kemampuan kognitif tutees, 5) Tahap cognitive phase, yaitu tahap interaksi antara tutor dan tutees dalam rangka intelektualisasi dan pemahaman materi (Zone Proximal Development) dilakukan minimal 4 kali/session, 6) Tahap post-test kemampuan tuttes setelah dilakukan peer-tutor

Metode pengumpulan data yang digunakan adalah tes menggunakan multiple choice questions (MCQ) sejumlah 25 soal dengan model soal vignete yang disusun oleh peneliti dengan tim pengajar. Instrumen penelitian sebelumnya telah dilakukan review oleh tim pengajar dan dilanjutkan dengan uji validitas dan reliabilitas pada tanggal 12 Januari 2017 di prodi Diploma III Keperawatan FIK Universitas Muhammadiyah Ponorogo. Hasil uji validitas instrumen dengan Pearson Product Moment, instrumen dinyatakan valid dengan nilai corrected item-total correlation lebih besar dari koefisien korelasi minimal (>0.444) sehingga instrumen dapat digunakan. Instrumen juga dinyatakan reliable setelah dilakukan uji Cronbach Alpha, nilai sebesar $0.746>0,6$. Hal ini menunjukkan bahwa instumen memiliki reliabilitas yang tinggi sehingga dapat digunakan untuk mengukur kompetensi kognitif mahasiswa.

Kompetensi kognitif mahasiswa diukur sebanyak 2 kali, yaitu pre-test (sebelum mendapatkan perlakuan). Setelah mahasiswa mendapatkan intervensi berupa pemberian materi dengan menerapkan metode pembelajaran peer-assisted learning (pada kelompok eksperimen) dan metode pembelajaran konvensional ceramah (kelompok kontrol), selanjutnya dilakukan posttest untuk mengevaluasi kompetensi kognitif mahasiswa.

Setelah semua data terkumpul selanjutnya dilakukan uji normalitas dan homogenitas data. 
Uji normalitas dengan Kolmogorov-smirnov, sedangkan uji homogenitas dengan Levene's Test of Equality Variances. Tehnik analisa data untuk menguji hipotesis penelitian dengan menggunakan statistik parametrik. Hal ini dikarenakan hasil dari uji normalitas dan homogenitas data menunjukkan data berdistribusi normal dan tidak ada perbedaan signifikan dari kedua varians. Analisis data yang digunakan untuk menjawab hipotesis adalah uji paired $t$-test untuk melihat perbedaan rata-rata kompetensi kognitif pre-test dan post-test.
Sedangkan untuk melihat perbedaan metode peer-assisted learning dengan metode konvensional ceramah dilakukan uji Independent t-test.

\section{Hasil}

Hasil perhitungan uji normalitas menunjukkan bahwa kedua kelompok berdisribusi normal. Berdasarkan perhitungan analisis uji homogenitas menunjukkan varians kedua kelompok homogen.

Tabel 1.1 Perubahan Kompetensi Kognitif sebelum dan setelah perlakuan pada kelompok perlakuan dan kontrol mahasiswa Semester IV Akper Pemkab Ponorogo $(n=60)$

\begin{tabular}{rcrrr}
\hline Kelompok & Waktu Pengukuran & Mean & SD & p-value \\
\hline \multirow{2}{*}{ Perlakuan } & Pre-test & 42,40 & 9,83 & \multirow{2}{*}{0,000} \\
\multirow{2}{*}{ Kontrol } & Post-test & 84,27 & 7,04 & \\
& Pre-test & 40,67 & 8,01 & \multirow{2}{*}{0,000} \\
\hline
\end{tabular}

Sumber: Data Primer, 2017

Berdasarkan tabel 1.1 dapat diketahui bahwa mahasiswa kelompok intervensi sebelum perlakuan nilai mean $42,40+9,83$, termasuk dalam kategori tidak kompeten. Kompetensi meningkat setelah perlakukan menjadi $84,27+7,04$, termasuk kategori kompeten. Sedangkan pada kelompok kontrol sebelum perlakuan nilai mean $40,67+8,01$, termasuk dalam kategori tidak kompeten. Setelah mendapatkan intervensi non-PAL, nilai mean meningkat menjadi $69,60+8,04$, tetap dalam kategori tidak kompeten. Rata-rata nilai kompetensi kognitif pada kelompok eks perimen lebih tinggi dibandingkan dengan kelompok kontrol. Hasil uji Paired t-test didapatkan $\rho=$ $0.000(\rho<0,05)$. Hal itu berarti ada perbedaan rata-rata kompetensi kognitif mahasiswa pre-test dan post-test.

Hasil uji statistik Independet $t$-test didapatkan $\rho=$ 0.000 , artinya $\rho$-value $<\alpha(0.05)$. Artinya $\mathrm{H} 1$ diterima, sehingga dapat disimpulkan ada pengaruh penerapan metode pembelajaran peerassisted learning terhadap kompetensi kognitif mahasiswa.

\section{Pembahasan}

Hasil penelitian menunjukkan bahwa terjadi peningkatan kompetensi kognitifpada kelom pok perlakuan dan kelompok kontrol setelah mendapatkan perlakuan (intervensi). Nilai mean kompetensi kognitif kelompok perlakuan pada saat pre-test termasuk kategori tidak kompeten dan mean pada saat post-test meningkat menjadi kategori kompeten. Sedangkan nilai mean kompetensi domain kognitif mahasiswa kelompok kontrol pada saat pre-test termasuk kategori tidak kompeten kemudian mengalami peningkatan nilai mean tapi tidak berubah kategoriya adalah tidak kompeten pada saat posttest.

Stanberg (1985, cit. Topping, 1996) menyebutkan bahwa ada beberapa komponen yang teridentifikasi dan mungkin mengalami peningkatan selama proses PAL diantaranya: kemampuan meta-kognitif dalam merencanakan, memonitor, dan mengevaluasi diri dalam mengajar. Selain itu, dimungkinkan juga adanya peningkatan dalam menilai, terkait dengan penggunaan pengetahuan deklaratif, pengetahuan prosedural dan kontekstual. Maksudnya adalah seorang mahasiswa ketika menjadi tutor PAL, dalam proses mengajarkan keterampilan, sebenarnya dengan sendirinya dia akan belajar dan terus belajar cara mengajaryang baik. Termasuk di dalamnya cara menyampaikan suatu materi keterampilan agar lebih mudah dicerna oleh peserta, pemilihan kata yang tepat 


\section{NONRSEINANG \\ PRACTICES}

bahkan memberikan contoh yang mudah dipahami oleh mahasiswa pesertanya. Proses kognitif yang terjadi meliputi: proses memahami (perceiving), membedakan (differentiating), memilah (selecting), menyimpan (storing), menyimpulkan (inferring), menerapkan (applying), menggabungkan (combining), menilai (justifying), dan merespon (responding).

Peningkatan kompetensi kognitif mahasiswa pada kelompok yang diterapkan metode PAL sejalan dengan teori zone of proximal development oleh Vygotsky (1978), yang menyatakan bahwa perkembangan kognitif membutuhkan interaksi sosial. Vygotsky menetapkan bahwa interaksi sosial memainkan peran penting dalam pengembangan kognisi (Vygotsky, 1986). Proses interaksi antar mahasiswa merupakan proses belajar sebagai upaya memahami informasi yang baru (Brooks and Brooks, 1993; Eggen and Kauchak, 2012). Didukung juga dengan teori perkembangan kognitif Piaget, bahwa kerjasama diantara rekan sebaya (peer-tutor) mendorong pertukaran pemikiran dan diskusi secara nyata, dan kerjasama. Kerjasama diantara rekan sebaya penting untuk mengembangkan sikap, berfikir kritis, objektivitas, dan refleksi diskursif (Falchikov, 2001).

Perbedaan nilai ini dikarenakan tutor PAL dapat berfungsi dengan efektif, tutor yang memiliki keselarasan kognitif dengan tutee dan menguasai materi dengan baik mampu memberikan pemahaman kepada tutee.

Dalam penerapan peer-assisted learning, diharapkan tutor menjadi sumber belajar utama dan pemicu belajar bagi tutee (Gunarya, 2011). Berdasarkan tujuan pembelajaran yang berorientasi pada student center learning (SCL), pembelajaran peer-assisted learning mendorong tutor menggunakan kemampuan untuk lebih aktif berbagi informasi dengan tutee untuk mencapai solusi dan pemahaman serta mengelola pembelajarannya secara mandiri (Roscoe \& Chi, 2014).

Metode pembelajaran peer-assisted learning, memiliki dua komponen utama, yaitu menjelaskan dan mempertanyakan. Keduanya mempunyai dua unsur membangun pengetahuan (kognitif) dan memberitahukan pengetahuan. Seorang tutor dalam suatu kelompok, mendapatkan manfaat saat memberikan penjelasan pada tutee. Sebab saat memberikan informasi seorang tutor melakukan pengintegrasian konsep dan prinsip serta memunculkan ide baru. Selain itu, saat tutee bertanya dengan pertanyaan yang spesifik dan mendalam, maka akan mendukung tutee untuk merefleksikan pengembangan pengetahuan (kognitif), dimana seorang tutor berperan membantu proses ini sekaligus menguatkan pemahamannya (Roscoe \& Chi, 2014; (Depaz \& Moni, 2012). Model pembelajaran peer-assisted learning membantu tutor membangun metakognisi, merefleksikan pengetahuan dan pengalaman, serta mengkonstruksi pengetahuan dengan cara menyimpulkan maupun menyatukan ide. Hal tersebut yang menyebabkan adanya peningkatan kompetensi kognitif mahasiswa pada kelompok perlakuan. Stanberg (1985, cit. Topping, 1996) menyebutkan bahwa ada beberapa komponen yang teridentifikasi dan mungkin mengalami peningkatan selama proses PAL diantaranya: kemampuan meta-kognitif dalam merencanakan, memonitor, dan mengevaluasi diri dalam mengajar.

Penelitian ini melibatkan responden remaja, dimana pada masa ini terdapat tugas-tugas sesuai fase perkembangan. Salah satu tugas perkembangan fase remaja adalah interaksi intens dengan teman untuk mengembangkan kecakapan intelektual dan konsep-konsep tentang kehidupan sosial (Monks, Knoers, \& Haditono, 2012). Sejalan dengan pendapat Inhelder dan Piaget bahwa perubahan otak pada masa remaja dibutuhkan untuk perkembangan kognitif, melalui bertukar ide dengan teman sebaya akan meningkatkan perkembangan berfikir secara operasional.

Keterbatasan dari penelitian diantaranya: peneliti tidak melakukan eksplorasi gaya belajar, motivasi tutor dan tutee, beban belajar mahasiswa, observasi proses PAL hanya pada satu kompetensi. Selain itu, responden yang dilibatkan dalam penelitian, baik kelompok perlakuan atau kontrol adalah mahasiswa dalam satu institusi, 
sehingga kemungkinan kedua kelompok bertemu dan berdiskusi diluar proses pembelajaran tidak dapat dikendalikan oleh peneliti.

Implikasi dari penelitian ini diharapkan metode PAL membantu mahasiswa dalam membangun kerangka konseptual (constructivism) pengetahuan dan keterampilan. Melalui pembelajaran PAL, mahasiswa akan berlatih untuk mengasah kemampuan kognitif, menyampaikan ide pada teman belajar, dan berlatih komunikasi dua arah antara tutor dan tutee.

\section{Kesimpulan}

Pembelajaran dengan metode peer-assisted learning (PAL) dan metode konvesional (ceramah) berpengaruh terhadap pencapaian kompetensi mahasiswa semester IV di Akper Pemkab Ponorogo. Metode pembelajaran PAL mempunyai pengaruh signifikan untuk meningkatkan kompetensi kognitif mahasiswa.

Hasil penelitian ini diharapkan menjadi land asan institusi untuk menjadikan PAL sebagai salah satu alternatif strategi pembelajaran student centered learning $(\mathrm{SCL})$ pada materi. Peneliti selanjutnya diharapkan dapat melanjutkan penelitian dengan desain eksperimen murni dengan mengendalikan faktor-faktor yang mempengaruhi kompetensi mahasiswa, misalnya gaya belajar, motivasi, lingkungan belajar dll, selain itu juga perlu mempertimbangkan untuk melibatkan responden yang berbeda lokasi penelitian untuk kelompok kontrol dan eksperimen sehingga masing-masing tidak saling mempengaruhi.

\section{Referensi}

Brooks, J.G., \& Brooks, M.G. (1993). In Search of Understanding: The Casefor Constructivist Classrooms. Alexandria, VA: Association for Supervisio and Curriculum Development.

Brown, G., \& Atkins, M. (2002). Effective Teaching in Higher Education. London: Taylor and Francis e-Library.

Buckley, S. \& Zamora, J. (2007). Effects of participation in a cross year peer tutoring program in clinical examination skills on volunteer tutor's skills and attitudes toward teachers and teaching. BMC Med Education. 7; 20.
Depaz, I., \& Moni, R. (2012). Using peer-teaching to support co-operative learning in undergraduate pharmacology. Biosciences Education Jaournal, 11; 98108.

Eggen, Paul \& Kauchak, Don. (2012). Strategi dan Model Pembelajaran Mengejar Konten dan Ketrampilan Berfikir. Jakarta: Indeks.

Falchikov, N. (2001). Learning Together: Peer Tutoring in Higher Education. London: Routledge Falmer.

Gunarya, A. (2011, Maret 31). Model Perilaku Belajar. Retrieved from http://repository.unhas.ac.id/handle/123 456789/27

Henning, J. M., Weidner, T. G., \& Mellisa, M. C. (2008). Peer Assisted Learning in Clinical Education: Literatur Review. Athletic Training Education Journal, 84-90.

Heron, T., Villareal, D., \& Yao, M. (2006). Peer Tutoring Systems: Application in Classroom and Specialized Enviroments. Reading \& Writtings Quarterly, 27-45.

Monks, F., Knoers, A., \& Haditono, S. (2012). Psikologi Perkembangan: Pengantar dalam Berbagai Bagiannya. Cetakan 14. Yogyakarta: Universitas Gadjah Mada.

Mulder, H. (2006). Competency Based Trainning: What, Why \& How? dalam Proceeding, Teaching Learning Procces \& Assesment in Competence Based Education.

Roscoe, R., \& Chi, M. (2014). Understanding tutor learning: knowledge building and knowledge telling in peer tutors explanation and questions. Review of Education Research, 77 (4); 534-574.

Ross, M., \& Cummings, A. (2009). Peer Assisted Learning, A practical guide for medical teachers Edisi 3. UK: Elsevier.

Secomb, J. (2008). A systematic review of peer teaching and learning in clinical education. Journal of clinical nursing. 17, pp. 703-16.

Stone, R., Cooper, S., \& Cant, R. (2013). The Value of Peer Learning in Undergraduate Nursing education: A Systematic Review. International Scholary Research Notice, 110.

Ten, C., \& Durning, S. (2007). Peer teaching in Medical Education: twelve reason to move from theory to practice. Medical teacher, 591-599. 


\section{NUERSSING \\ PRACTICES}

Topping, K. (1996). The Effectivenss of Peer Tutoring in Further ad Higher Education: A Typology and Review of the Literature. Higher Education, Vol. 32, o. 3, 321-345.

Vygotsky, L.S. (1978). Mind in Society: The Development of Higher Psychological Processes. Cambridge: MA: Harvard University Press.

Yu, T., Wilson, N., Singh, P., Lemanu, D., Hawken, S., \& Hill, A. (2011). Medical students-asteachers: a systematic review of peerassisted teaching during medical school. Advance in Medical Education and Practice Vol. 2, 157-172. 